\title{
The Relative Sexual Dimorphism of Human Incisor Crown and Root Dimensions
}

\author{
Edward F. Harris* and W. Max Couch, Jr. \\ Department of Orthodontics, University of Tennessee, Memphis, TN 38163
}

\begin{abstract}
Teeth are unusual structures in that their dimensions are sexually dimorphic even though they form early in life, several years before steroid-mediated adolescence. These size differences make teeth attractive as indicators of a specimen's sex. Alternatively, the magnitude of sexual dimorphism in humans is low, so there is considerable overlap in sizes between the two sexes. Prior studies suggest that tooth root dimensions are more dimorphic than crown dimensions, so roots would be more useful for sex determination. To explore this, we measured the four incisor tooth types from standardized periapical radiographs in a sample
\end{abstract}

Human tooth crown dimensions exhibit little sexual dimorphism, which detracts for their usefulness for sex determination (Ditch and Rose, 1972; De Vito and Saunders, 1990). Garn et al. (1967) showed that sexual dimorphism in a sample of American whites is only on the order of $3-5 \%$, making them substantially less dimorphic than any of the other higher primates (e.g., Swindler, 2002; Koppe and Swindler, 2004). The canines characteristically are the most dimorphic (ca. 6\%), notably their buccolingual widths.

Sexual dimorphism in tooth size is useful in forensic settings (Teschler-Nicola and Prossinger, 1998) and also in archeological settings when the more informative skeletal elements are immature or absent (Krogman and Iscan, 1986; Ubelaker, 1999). That sex differences occur at all in the primary and permanent teeth is of interest because they depend on hormonal differences that preferentially develop size and shape in one sex over the other well before the onset of steroid-mediated adolescence (Tanner et al., 1959; Manning, 2002).

We have collected incisor crown and root dimensions from a contemporary sample of American whites, and the purpose of this paper is to assess the relative sexual discriminating effectiveness of these crown and root variables.

\section{MATERIALS AND METHODS}

Incisor dimensions were obtained from standardized periapical radiographs using a computer assisted measurement system. Data were collected from 148 adolescent American white adolescents (57 males, 91
( $n=148$ ) of living American white adolescents. Root lengths are somewhat more dimorphic than crown sizes in this sample (ca. $6 \%$ vs. $2 \%$ ), and this translates into somewhat higher discriminatory power. The hindrance, however, is that all crown and root sizes are positively intercorrelated, so there is effectively just one dentition-wide axis of "tooth size" variation. Statistically, at least for these incisor tooth types, there is no added discriminatory power in the crown sizes once root dimensions have been accounted for, though the addition of data from other tooth types might improve discrimination somewhat. Dental Anthropology 2006;19(3):87-95.

females). These were healthy, phenotypically normal teenagers (mean age 14 years). All of the teeth were caries-free, and none had been treated orthodontically, which typically reduces root length due to external apical root resorption (Brezniak and Wasserstein, 1993a,b). Subjects were old enough to ensure root apexification, which is completed for the incisors around 10 years of age (Harris and McKee, 1990). Radiographs had been taken by an experienced dentist using a long-cone paralleling technique. Teeth with rotations or angulations affecting tooth-to film orientations were omitted from analysis. Radiographs give a proper measure of crown height since the cementoenamel junction is not obscured by the gingiva ( $c f$. Rhee and Nahm, 2000).

Radiographs were digitized at 1,200 dpi and 256greyscale. SigmaScan 5.0 (SPSS Inc., Chicago, IL) was used to obtain crown and root dimensions, which were corrected for magnification prior to statistical analysis. The screen image of each tooth was magnified severalfold, which enhances landmark location but does not affect the dimensions obtained. The tooth with better image quality and alignment was chosen from each left-right pair. If there was no difference, the tooth in the left quadrant was analyzed, so sample sizes are of individuals, not teeth.

${ }^{*}$ Correspondence to: Edward F. Harris, Department of Orthodontics, University of Tennessee, Memphis, TN 38163.

E-mail: eharris@utmem.edu 
Full-mouth dental casts were taken along with the periapical radiographs, and we measured the maximum mesiodistal crown dimensions of the teeth using sliding calipers, which provide an absolute measure of tooth size as well an internal check of the radiographic method. Four dimensions are evaluated here, (1) mesiodistal crown width, (2) overall tooth length, (3) crown height, and (4) root length.

Overall tooth length was measured from the root apex coronally to the mediolateral midpoint of the tooth's incisal edge (Fig. 1). Root length - from the root apex to the cementoenamel junction (CEJ) - is not an invariant distance because the CEJ undulates around the tooth's periphery (Zeisz and Nuckolls, 1949), with the CEJ higher (more occlusal) on the tooth's mesial and distal aspects than labially or lingually. We measured the straight-line distance from the root apex separately to the mesial and the distal margins of the CEJ. For the present study, the average of these two distances was used as root length. This distance was subtracted on an individual basis from tooth length to yield crown height. In sum, tooth length equals crown height plus root length.

Sexual dimorphism was assessed statistically using factorial analysis of variance (Winer et al., 1991) and stepwise multivariate discriminant functions analysis (Cooley and Lohnes, 1971). Principal components analysis (Gorsuch, 1983) was performed to evaluate the statistical associations among the variables. Statistics were calculated using the JMP software package (SAS Institute Inc., Cary, NC).

\section{RESULTS}

\section{Tooth Dimensions}

Of the four incisor tooth types, mesiodistal crown diameter of just the upper central incisor (U1) exhibits

TABLE 1. Descriptive incisor dimensions, by sex, and tests for sexual dimorphism ${ }^{1}$

\begin{tabular}{|c|c|c|c|c|c|c|c|c|c|c|c|c|}
\hline \multirow[b]{2}{*}{ Tooth } & \multicolumn{4}{|c|}{ Males } & \multicolumn{4}{|c|}{ Females } & \multirow{2}{*}{$\begin{array}{c}\text { \% Sex } \\
\text { Dimorphism }\end{array}$} & \multirow{2}{*}{$\begin{array}{c}\text { Adjusted } \\
\mathrm{r}^{2} \%\end{array}$} & \multicolumn{2}{|c|}{ Analysis of Variance } \\
\hline & $\mathrm{n}$ & $\bar{x}$ & $\mathrm{sd}$ & sem & $\mathrm{n}$ & $\bar{x}$ & $\mathrm{sd}$ & sem & & & F-ratio & P value \\
\hline \multicolumn{13}{|c|}{ Crown Width } \\
\hline U1 & 57 & 9.23 & 0.81 & 0.11 & 91 & 8.91 & 0.59 & 0.06 & 3.69 & 4.61 & 8.10 & 0.0051 \\
\hline U2 & 55 & 6.98 & 0.60 & 0.08 & 90 & 6.90 & 0.62 & 0.06 & 1.15 & $(-0.30) \#$ & 0.57 & 0.4497 \\
\hline L1 & 56 & 5.41 & 0.46 & 0.06 & 91 & 5.32 & 0.40 & 0.04 & 1.82 & 0.54 & 1.79 & 0.1828 \\
\hline L2 & 57 & 6.07 & 0.51 & 0.07 & 90 & 5.97 & 0.39 & 0.04 & 1.72 & 0.64 & 1.93 & 0.1666 \\
\hline \multicolumn{13}{|c|}{ Tooth Length } \\
\hline U1 & 57 & 26.36 & 2.49 & 0.33 & 91 & 25.21 & 2.14 & 0.22 & 4.56 & 5.11 & 8.91 & 0.0033 \\
\hline U2 & 56 & 25.15 & 2.42 & 0.32 & 90 & 23.78 & 1.95 & 0.21 & 5.76 & 8.29 & 14.11 & 0.0002 \\
\hline L1 & 56 & 22.48 & 2.22 & 0.30 & 91 & 21.60 & 1.86 & 0.19 & 4.08 & 3.76 & 6.70 & 0.0106 \\
\hline L2 & 57 & 23.90 & 2.54 & 0.34 & 91 & 23.04 & 1.87 & 0.20 & 3.71 & 2.99 & 5.54 & 0.0199 \\
\hline \multicolumn{13}{|c|}{ Crown Height } \\
\hline U1 & 57 & 8.40 & 1.00 & 0.13 & 91 & 8.24 & 0.86 & 0.09 & 1.93 & 0.04 & 1.06 & 0.3042 \\
\hline U2 & 56 & 7.45 & 0.86 & 0.11 & 90 & 7.14 & 0.69 & 0.07 & 4.31 & 3.10 & 5.64 & 0.0189 \\
\hline L1 & 56 & 7.05 & 1.01 & 0.14 & 91 & 7.14 & 0.86 & 0.09 & -1.19 & $(-0.49) \#$ & 0.30 & 0.5874 \\
\hline $\mathrm{L} 2$ & 57 & 7.23 & 0.95 & 0.13 & 91 & 7.23 & 0.81 & 0.08 & -0.01 & $(-0.69) \#$ & 0.00 & 0.9961 \\
\hline \multicolumn{13}{|c|}{ Root Length } \\
\hline U1 & 57 & 17.95 & 1.98 & 0.26 & 91 & 16.96 & 1.86 & 0.20 & 5.84 & 5.45 & 9.47 & 0.0025 \\
\hline $\mathrm{U} 2$ & 56 & 17.70 & 1.99 & 0.27 & 90 & 16.64 & 1.75 & 0.18 & 6.38 & 6.70 & 11.41 & 0.0009 \\
\hline L1 & 56 & 15.43 & 1.70 & 0.23 & 91 & 14.47 & 1.38 & 0.14 & 6.68 & 8.34 & 14.29 & 0.0002 \\
\hline L2 & 57 & 16.67 & 1.96 & 0.26 & 91 & 15.81 & 1.39 & 0.15 & 5.41 & 5.55 & 9.64 & 0.0023 \\
\hline \multicolumn{13}{|c|}{ Crown-Root Ratio } \\
\hline U1 & 57 & 0.47 & 0.07 & 0.01 & 91 & 0.49 & 0.07 & 0.01 & -3.95 & 1.19 & 2.77 & 0.0981 \\
\hline U2 & 56 & 0.42 & 0.06 & 0.01 & 90 & 0.43 & 0.06 & 0.01 & -2.14 & $(-0.09) \#$ & 0.86 & 0.3542 \\
\hline L1 & 56 & 0.46 & 0.07 & 0.01 & 91 & 0.50 & 0.06 & 0.01 & -7.17 & 5.98 & 10.29 & 0.0016 \\
\hline L2 & 57 & 0.44 & 0.06 & 0.01 & 91 & 0.46 & 0.05 & 0.01 & -4.80 & 3.20 & 5.86 & 0.0168 \\
\hline
\end{tabular}

${ }^{1}$ Tooth codes are maxillary central (U1) and lateral (U2) incisor and mandibular central (L1) and lateral (L2) incisor. Sexual dimorphism is calculated from the means, ((M-F)/F) times 100. Ajusted $\mathrm{r}^{2}$ is the variation in the tooth dimension accounted for by sexual dimorphism (the independent variable) in the analysis of variance.

\#The $\mathrm{r}^{2}$ is close to zero, and the adjustment caused the estimate to be negative, though this has no statistical interpretation (and should be set to zero). 
TABLE 2. Matrix of Pearson correlation coefficients for the 16 incisor dimensions studied ${ }^{1}$

\begin{tabular}{lcccccccccccccccc}
\hline & U1 & U2 & L1 & L2 & U1 & U2 & L1 & L2 & U1 & U2 & L1 & L2 & U1 & U2 & L1 & L2 \\
& CW & CW & CW & CW & TL & TL & TL & TL & CH & CH & CH & CH & RL & RL & RL & RL \\
\hline U1 CW & 1.00 & 0.55 & 0.62 & 0.58 & 0.35 & 0.32 & 0.43 & 0.44 & 0.45 & 0.35 & 0.35 & 0.39 & 0.21 & 0.23 & 0.35 & 0.36 \\
U2 CW & 0.55 & 1.00 & 0.52 & 0.54 & 0.27 & 0.34 & 0.19 & 0.22 & 0.29 & 0.38 & 0.23 & 0.32 & 0.19 & 0.23 & 0.11 & 0.11 \\
L1 CW & 0.62 & 0.52 & 1.00 & 0.68 & 0.27 & 0.23 & 0.48 & 0.44 & 0.41 & 0.31 & 0.48 & 0.42 & 0.13 & 0.14 & 0.34 & 0.34 \\
L2 CW & 0.58 & 0.54 & 0.68 & 1.00 & 0.21 & 0.18 & 0.38 & 0.38 & 0.31 & 0.26 & 0.44 & 0.43 & 0.11 & 0.11 & 0.23 & 0.27 \\
U1 TL & 0.35 & 0.27 & 0.27 & 0.21 & 1.00 & 0.67 & 0.51 & 0.51 & 0.56 & 0.38 & 0.26 & 0.33 & 0.93 & 0.62 & 0.51 & 0.49 \\
U2 TL & 0.32 & 0.34 & 0.23 & 0.18 & 0.67 & 1.00 & 0.54 & 0.53 & 0.35 & 0.51 & 0.23 & 0.32 & 0.64 & 0.94 & 0.56 & 0.51 \\
L1 TL & 0.43 & 0.19 & 0.48 & 0.38 & 0.51 & 0.54 & 1.00 & 0.88 & 0.36 & 0.26 & 0.67 & 0.59 & 0.45 & 0.51 & 0.90 & 0.82 \\
L2 TL & 0.44 & 0.22 & 0.44 & 0.38 & 0.51 & 0.53 & 0.88 & 1.00 & 0.35 & 0.32 & 0.62 & 0.67 & 0.45 & 0.48 & 0.78 & 0.93 \\
U1 CH & 0.45 & 0.29 & 0.41 & 0.31 & 0.56 & 0.35 & 0.36 & 0.35 & 1.00 & 0.48 & 0.46 & 0.44 & 0.21 & 0.21 & 0.19 & 0.22 \\
U2 CH & 0.35 & 0.38 & 0.31 & 0.26 & 0.38 & 0.51 & 0.26 & 0.32 & 0.48 & 1.00 & 0.32 & 0.38 & 0.24 & 0.18 & 0.15 & 0.22 \\
L1 CH & 0.35 & 0.23 & 0.48 & 0.44 & 0.26 & 0.23 & 0.67 & 0.62 & 0.46 & 0.32 & 1.00 & 0.77 & 0.10 & 0.13 & 0.28 & 0.40 \\
L2 CH & 0.39 & 0.32 & 0.42 & 0.43 & 0.33 & 0.32 & 0.59 & 0.67 & 0.44 & 0.38 & 0.77 & 1.00 & 0.19 & 0.22 & 0.31 & 0.35 \\
U1 RL & 0.21 & 0.19 & 0.13 & 0.11 & 0.93 & 0.64 & 0.45 & 0.45 & 0.21 & 0.24 & 0.10 & 0.19 & 1.00 & 0.63 & 0.51 & 0.48 \\
U2 RL & 0.23 & 0.23 & 0.14 & 0.11 & 0.62 & 0.94 & 0.51 & 0.48 & 0.21 & 0.18 & 0.13 & 0.22 & 0.63 & 1.00 & 0.58 & 0.50 \\
L1 RL & 0.35 & 0.11 & 0.34 & 0.23 & 0.51 & 0.56 & 0.90 & 0.78 & 0.19 & 0.15 & 0.28 & 0.31 & 0.51 & 0.58 & 1.00 & 0.82 \\
L2 RL & 0.36 & 0.11 & 0.34 & 0.27 & 0.49 & 0.51 & 0.82 & 0.93 & 0.22 & 0.22 & 0.40 & 0.35 & 0.48 & 0.50 & 0.82 & 1.00 \\
\hline
\end{tabular}

${ }^{1}$ Variable codes are crown width (CW), tooth length (TL), crown height $(\mathrm{CH})$, and root length (RL). Sample size was 148 individuals for all correlations, so coefficients above 0.16 are statistically significant $(\mathrm{P}<0.05$; Rohlf and Sokal, 1981).

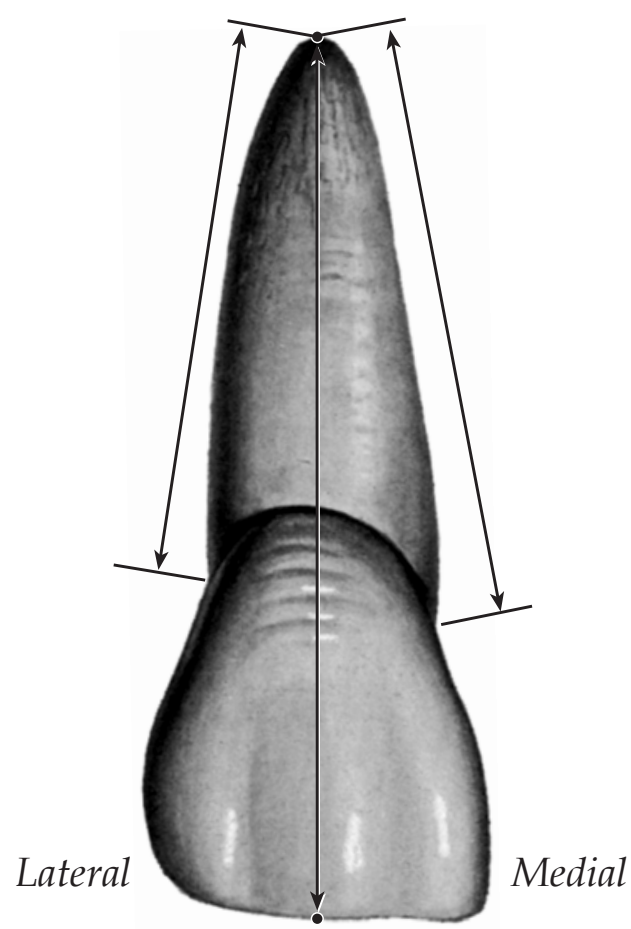

Fig. 1. Labial view of a maxillary right central incisor showing measurements of root length determined separately on the medial and lateral aspects (from root apex to CEJ) and tooth length (from root apex to midpoint of incisal edge). Crown height was operationalized as tooth length minus root length (i.e., average of medial and lateral distances), which yields a longer root length (and shorter crown height) than if the labial or lingual level of the CEJ had been used.
TABLE 3. Results of principal components analysis on 16 incisor dimensions, without rotation

\begin{tabular}{|c|c|c|c|c|}
\hline \multirow[b]{2}{*}{ Tooth } & \multicolumn{4}{|c|}{ Eigenvectors } \\
\hline & I & II & III & IV \\
\hline \multicolumn{5}{|c|}{ Crown Width } \\
\hline U1 & 0.061 & 0.044 & 0.038 & 0.177 \\
\hline U2 & 0.038 & -0.019 & -0.010 & 0.198 \\
\hline L1 & 0.034 & 0.048 & 0.029 & 0.112 \\
\hline $\mathrm{L} 2$ & 0.028 & 0.042 & 0.029 & 0.116 \\
\hline \multicolumn{5}{|c|}{ Tooth Length } \\
\hline U1 & 0.418 & -0.405 & 0.497 & 0.108 \\
\hline U2 & 0.382 & -0.276 & -0.535 & 0.248 \\
\hline L1 & 0.367 & 0.409 & 0.027 & 0.000 \\
\hline L2 & 0.371 & 0.423 & 0.073 & 0.065 \\
\hline \multicolumn{5}{|c|}{ Crown Height } \\
\hline U1 & 0.083 & -0.015 & 0.144 & 0.427 \\
\hline U2 & 0.063 & -0.026 & 0.006 & 0.313 \\
\hline L1 & 0.087 & 0.182 & 0.094 & 0.361 \\
\hline L2 & 0.086 & 0.121 & 0.063 & 0.330 \\
\hline \multicolumn{5}{|c|}{ Root Length } \\
\hline U1 & 0.335 & -0.390 & 0.353 & -0.320 \\
\hline U2 & 0.319 & -0.250 & -0.542 & -0.065 \\
\hline L1 & 0.280 & 0.228 & -0.067 & -0.361 \\
\hline L2 & 0.285 & 0.302 & 0.010 & -0.265 \\
\hline Eigenvalue & 21.164 & 5.475 & 2.785 & 1.836 \\
\hline Percent & 61.847 & 16.000 & 8.138 & 5.365 \\
\hline \multicolumn{5}{|l|}{ Cumulative } \\
\hline Percent & 61.847 & 77.847 & 85.986 & 91.351 \\
\hline
\end{tabular}


TABLE 4. Descriptive statistics for the principal components scores and tests for sexual dimorphism ${ }^{1}$

\begin{tabular}{|c|c|c|c|c|c|c|c|c|c|c|c|}
\hline \multirow[b]{2}{*}{ Axis } & \multicolumn{4}{|c|}{ Males } & \multicolumn{4}{|c|}{ Females } & \multirow{2}{*}{$\begin{array}{c}\text { Adjusted } \\
\mathrm{r}^{2} \% \\
\end{array}$} & \multicolumn{2}{|c|}{ Analysis of Variance } \\
\hline & $\mathrm{n}$ & $\bar{x}$ & $\mathrm{sd}$ & sem & $\mathrm{n}$ & $\bar{x}$ & $\mathrm{sd}$ & sem & & F-ratio & P value \\
\hline PC I & 54 & 1.582 & 4.886 & 0.665 & 89 & -0.960 & 4.160 & 0.441 & 6.563 & 10.97 & 0.0012 \\
\hline PC II & 54 & -0.136 & 2.537 & 0.345 & 89 & 0.082 & 2.223 & 0.236 & $(-0.503)^{\#}$ & 0.29 & 0.5912 \\
\hline PC III & 54 & -0.152 & 1.792 & 0.244 & 89 & 0.092 & 1.593 & 0.169 & $(-0.198)^{\#}$ & 0.72 & 0.3977 \\
\hline PC IV & 54 & -0.195 & 1.446 & 0.197 & 89 & 0.118 & 1.291 & 0.137 & 0.562 & 1.80 & 0.1815 \\
\hline
\end{tabular}

${ }^{1}$ Variable codes are principal component scores for axes I through IV.

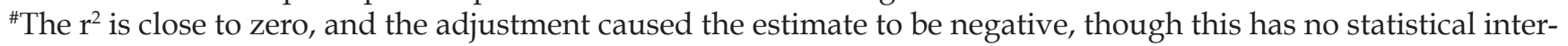
pretation (and should be set to zero).

significant sexual dimorphism (Table 1). Percentagewise, mean size for males is only $1-2 \%$ larger than for females. The other crown dimension assessed here, crown height, comparably exhibits little sexual dimorphism. Just the mean size difference for $\mathrm{U} 2$ is significant statistically (a $4 \%$ difference), and crown heights of the mandibular incisors are virtually identical in the two sexes.

It seems noteworthy that overall tooth lengths of all four incisors are appreciably more dimorphic. All four ANOVA tests are significant (Table 1). Percent sexual dimorphism is lower but not trivial in the mandible (ca. 3\%) and higher (ca. 5 to $8 \%$ ) in the upper arch. This greater sexual dimorphism likewise is reflected in the coefficients of determination $\left(\mathrm{r}^{2}\right)$ that can be read as the percentage of the variation in tooth length accounted for in the statistical sense by "sex." Percentages are lower for the two mandibular incisor types than in the maxilla, or, perhaps more correctly, the maxillary lateral incisor tooth length is comparatively highly dimorphic $\left(\mathrm{r}^{2}=\right.$ $14 \%)$.

It is evident that tooth length is composed of crown height and root length and, since sex differences in crown height are minor, most of the dimorphism obviously is due to sex differences in root length (Table 1). Indeed, sexual dimorphism in incisor root lengths is in the range of 5 to $8 \%$, which is noticeably higher than for crown widths or heights. Also, unlike crown dimensions, percentage sex differences are not smaller for the mandibular root dimensions.

\section{Crown-Root Ratios}

Incisor crown-root ratios (Table 1) were here assessed for completeness. The ratio is simply crown height divided by root length, so the larger the ratio the more crown height contributes to overall tooth length. Ratios are $50 \%$ or less, showing that incisor root lengths characteristically are more than twice their crown heights. Mean crown-root ratios are slightly larger in the mandible because the mandibular root lengths are proportionately shorter. Sexual dimorphism for these ratios is trivial in the maxillary incisors, whereas both tests are significant for the mandibular incisor types.
These mandibular differences are due to longer roots in males (whereas the crown heights are very similar in men and women).

\section{Correlation Matrix}

Several studies have shown that tooth crown diameters are positively intercorrelated (reviewed, e.g., in Henderson, 1975), and Garn et al. (1978a) showed that root lengths within individuals likewise covary in a positive fashion. These expectations are evident in the present data (Table 2) where all 120 pairwise correlations are positive and most are significantly different from zero statistically. Given the uniform sample size of 148 cases, correlations above 0.16 are significant $(\mathrm{P}<0.05)$ and those above 0.21 are highly significant $(\mathrm{P}<0.01)$.

Scanning the matrix, the weakest correlations are between crown widths and root lengths, and the strongest are between tooth lengths and root lengths. These latter are predictable, however, because root length is the major constituent of tooth length. Pearson and Davin (1924; also see Solow, 1966) term these sorts of correlations of a dimension plus part of itself "spurious" in the sense that they are correlated simply because of their geometric association, which need not be biological.

Ideally, one would like to find statistically independent axes of variation so that the sexual dimorphism exhibited by some tooth dimensions is not duplicative of that of other dimensions. Separate "axes" of variation would provide greater statistical power for discriminating between the sexes using multiple tooth dimensions. Given the consistently positive, generally high correlations here (Table 2) suggests that there is effectively just a single statistical (and, by inference, biological) axis of sexual dimorphism.

\section{Principal Components Analysis}

PCA (Gorsuch, 1983) was used to assess the relationships among the crown and root dimensions. Four dimensions for each of the four incisor tooth types were used in the analysis, namely (1) crown width, (2) tooth length, (3) crown height, and (4) root length. Four components were extracted with eigenvalues exceeding 

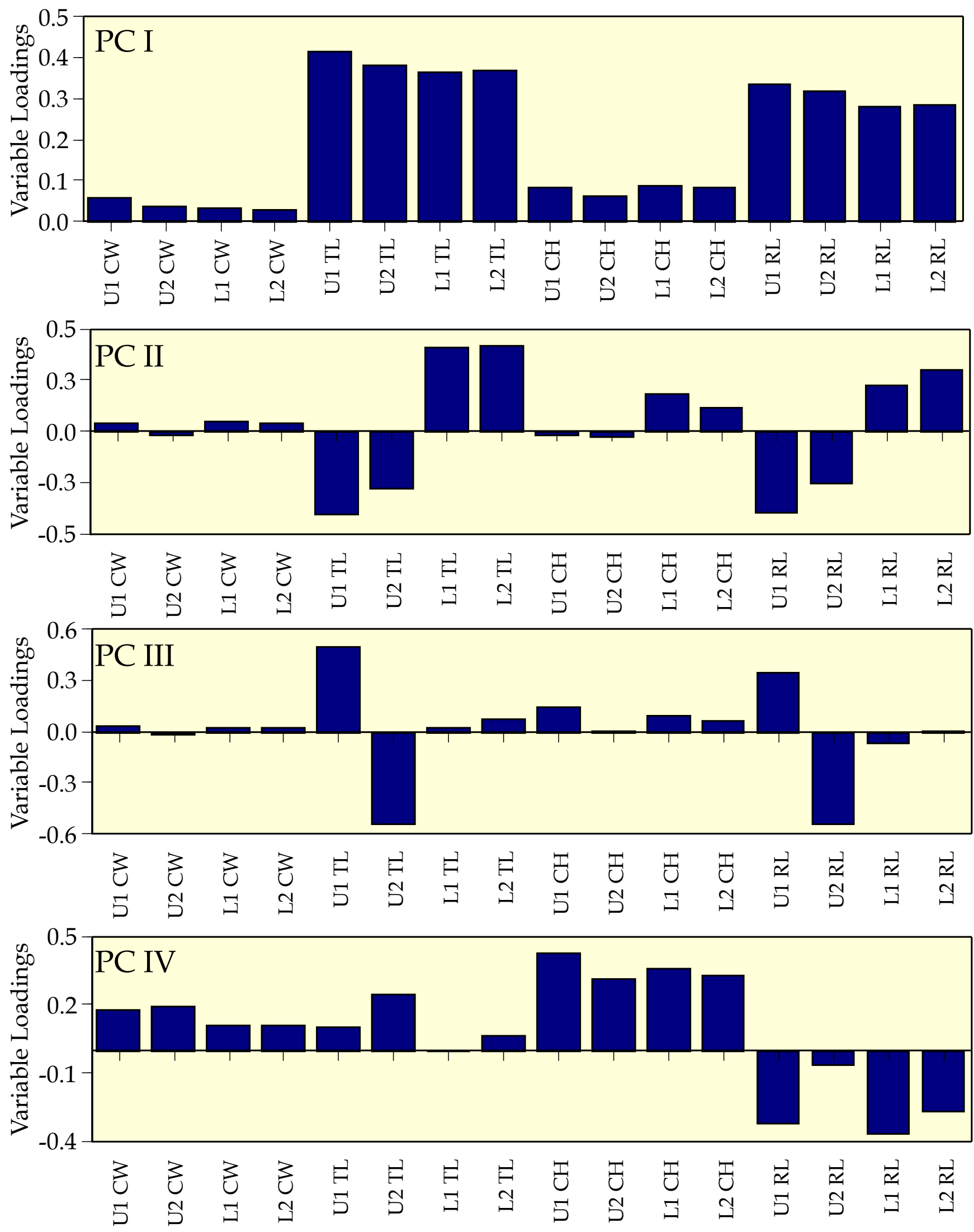

Fig. 2. Plots of the variable weights on the first four principal components extracted from the covariance matrix of 16 crown and root dimensions. These "weights" of variables with each canonical axis can be interpreted as the correlation coefficient of the variables with the axis. 
one (Kaiser, 1970), and these were evaluated without matrix rotation (Table 3). These four axes account for most $(91 \%)$ of the variation, and, within these, just the first axis is responsible for most (62\%) of the total variance.

PC I is controlled by tooth length, with slightly higher weightings on the two maxillary dimensions (Fig. 2). Probably because root lengths are major constituents of tooth length (Fig. 1), root lengths also have comparatively high weights on this component.

PC II reflects the high loadings of tooth lengths and root lengths, but here there are polarities (opposite signs) for variables in the maxilla and the mandible. As with the first component, crown widths and heights have only minor loadings (correlation coefficients) with PC II.

PC III is a further orthogonal axis of variation for root length and, by association, tooth length. Here just the maxillary variables exhibit high loadings, with polarities between the central and lateral incisors. In other words, having accounted for the variances of PC I and II, the remaining major axis of variation is a contrast between root lengths of the two maxillary incisor types.

Highly weighted variables for PC IV are restricted to crown heights and root lengths (Fig. 2). Within a variable (crown height or root length), all four weights are of the same sign.

When tested for sexual dimorphism (Table 4), PC I scores, which depend primarily on root lengths, are highly significant. In contrast, none of the other three axes seems to be of any value for sex discrimination.

\section{Discriminant Analysis}

When the eight crown size variables (4 widths, 4 heights) were subjected to stepwise linear discriminant function analysis, just one variable-crown width of U1-was significantly predictive. Correct allocation was $47 \%$ overall, though somewhat higher in girls (56\%) than boys (37\%).

When the other eight variables were analyzed (4 tooth lengths, 4 root lengths), again there was just one significant predictor because of the considerable
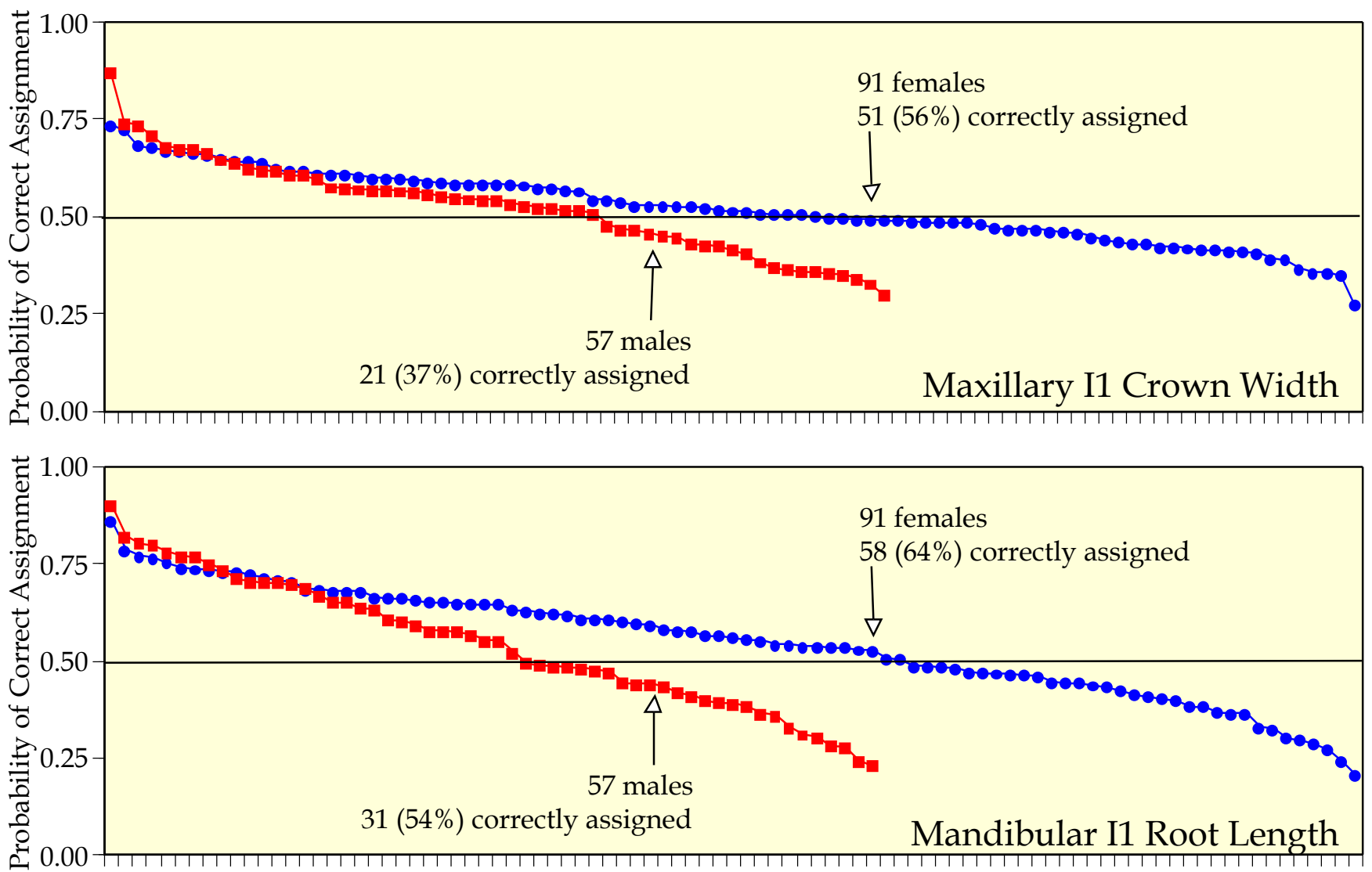

Fig. 3. Sequenced arrays of the probabilities of group assignment. Probabilities above $50 \%$ are the cases correctly assigned; cases with probabilities below $50 \%$ were allocated to the wrong sex. The height of the symbol above the 0.5 line is a measure of how confident the researcher can be that the case is correctly classified. The shallow slop of the distributions illustrates the weak sexual dimorphism even of these selected variables. Top. Arrays using U1 crown width, which is the one statistically significant crown size predictor of sex from among the 8 tested. Bottom. Arrays using mandibular I1 root length, which is the one significant root size predictor of sex in this sample from among the 8 tested. 
statistical redundancy of these dimensions. Here, mandibular central incisor (L1) root length was most discriminating, with $60 \%$ correct assignment (54\% for males; $64 \%$ for females). This is an improvement over using crown widths alone, but the increase in correct assignment $(60 \%$ vs. $49 \%)$ is modest. One can see from the very gradual slope of probabilities of correct assignment (Fig. 3) that there is considerable overlap in crown and in root dimensions between the two sexes.

We supposed that there would be enough statistical independence between crown and root dimensions that they could be used in combination to improve sex determination. This was not the case. Once the greater dimorphism of root length was entered (specifically, inclusion of L1 root length at step 1) and statistics of the other variables were adjusted to account for root length, none of the other dimensions had significant independent power to be added. With hindsight, this is because all 16 of the variables studied here are positively intercorrelated, and even the weakest associations (between crown widths and root lengths) are still on the order of 0.1 to 0.2 .

\section{DISCUSSION}

Tooth root size and morphology have been studied far less than crown size (e.g., Kovacs, 1971; Thomas, 1995), largely because of their inaccessibility and, additionally, in archeological specimens, their comparative fragility. So too, little is known about the genetic control of root size and morphology. Most root formation occurs prior to tooth emergence (Carlson, 1944), which may be protective against forces of mastication until teeth are in function. Unlike enamel, a root's configuration is subject to surface remodeling. Root resorption can be instigated with orthodontic forces (Harris, 2000) or with jiggling forces that are common consequences of pathological loss of supporting crestal bone (Nyman et al., 1978; Harris et al., 1993).

The accretion of cementum, in contrast, increases root dimensions in an age-progressive manner (WittwerBackofen et al., 2004), though the annual depositions are too small to be visualized on conventional radiographs. Cementum accumulation typically is thickest in the bifurcations of multirooted teeth, though hypercementosis occasionally occurs periapically (e.g., Halstead and Hoard, 1991).

The normal age-progressive periapical accumulation of cementum needs to be studied in more detail; researchers have reported on an increase in root length-supposedly by cementum apposition-as an age-progressive event. Most such studies have been cross-sectional (Levers and Darling, 1983; Whittaker et al., 1990), though there is some longitudinal evidence for root lengthening with age (Bishara et al., 1999).

The prime focus in the present study was to test whether root lengths exhibit greater sexual dimorphism than crown dimensions, where sex differences are too subtle to be definitive in most cases (Ditch and Rose, 1972; Kieser and Groeneveld, 1989). Precisely because sexual dimorphism is modest in humans, most studies that have developed discriminant functions capitalize on sex differences specific to their own sample; applications to other groups generally exhibit much weaker frequencies of correct sex assignment. The problem is intrinsic to the crown size data, not to sophistication of the statistical techniques. There are two synergistic problems, (1) there is little sexual dimorphism (the canines, especially buccolingually, seem to be the most dimorphic; Sciulli et al., 1977) and (2) even though teeth are numerous within a person, crown sizes all are significantly, positively intercorrelated, so there are few axes of novel information to exploit (e.g., Moorrees and Reed, 1964; Potter et al., 1968; Harris and Bailit, 1988); the sexual dimorphism seen among crown dimensions is statistically redundant.

These observations seem to have motivated Garn and coworkers (1979) and others to look for independent axes of variation. Tooth roots seem to offer two advantages here: (1) the dimensions are at least partially uncoupled from crown size (Fig. 2), so the data are not repetitive (statistically redundant) with crown dimensions, and (2) root lengths are a bit more dimorphic than crown dimensions (Table 1).

The present study has clear precedents in the work of Stanley Garn and colleagues (1978a,b, 1979) who measured root lengths in a sample of living American white teenagers using $45^{\circ}$ oblique-jaw radiographs. They measured five mandibular tooth types (C, P1, P2, M1, M2) omitting the incisors that are distorted in this radiographic view. While their methodological details differ from ours, there are some key similarities. One, we examined different teeth than Garn's group, but our intertooth correlations (Table 2) for tooth lengths are in the same range, about 0.5 to 0.6 , and the correlations within an arch are higher than between arches. Two, the correlations between crown size (here we tested mesiodistal incisor crown widths) and root lengths are low (ca. 0.1 to 0.2 ) but consistently positive. Garn et al. (1978b) found the same low level of crown-root integration.

Garn and coworkers (1979) tested the sex discriminatory power of numerous combinations of crown and root dimensions. Scrutiny of their presentation shows, however, that they made no effort to show that each variable in each discriminant function contributed significant statistically information. Alternatively, the simple addition of more variables typically will improve discrimination of individuals in the sample used to generate the formulae (discriminant functions) because using more variables capitalizes on variation unique to that sample. Unfortunately, amassing variables (1) does not improve the statistical significance of the predictive equation and (2) detracts from the generalizability of the results to other samples (Kieser and Groeneveld, 1989). 
In other words, "percentage correct allocation" should not be the driving criterion for developing discriminant functions because that criterion commonly is specific to the sample used to develop the functions - that criterion promotes exploiting male-female differences specific to that sample, not to sex differences in size relationships at large.

Tooth roots serve several functions (Shafer et al., 1983), including the important function of transmitting the forces of occlusion to the supporting alveolar bone. Given the significantly larger bite forces in males than females, especially after the onset of puberty (e.g., Bakke et al., 1990; Julien et al., 1996), the tendency for larger roots (with larger surface areas) in men probably is adaptive. As Garn noted (1978b, p 636):

It is impressive that the crowns of permanent teeth that begin to form by the second trimester of prenatal life and that complete their sizeattainment in the second to fifth year of postnatal life thus "anticipate" the length of still-to-becompleted roots by 10 years or more.

\section{CONCLUSIONS}

This study of incisor crown-root dimensions in a contemporary American white sample shows that root lengths are somewhat more sexually dimorphic than crown dimensions and, thus, are somewhat more useful for sex determination. The statistical associations are higher among crown dimensions than between crowns and roots, but all correlations are positive. Our discriminant function analysis (that relied just on incisor tooth types) does not support the supposition that combinations of crown and root dimensions are any more useful for sex determination than root dimensions alone-because the dimensions all seem to reflect the same statistical information. Perhaps the use of more tooth types, notably the canine, would somewhat improve correct sex assignment from tooth dimensions.

\section{LITERATURE CITED}

Bakke M, Holm B, Jensen BL, Michler L, Moller E. 1990. Unilateral, isometric bite force in 8-68-year-old women and men related to occlusal factors. Scand J Dent Res 98:149-158.

Bishara SE, Vonwald L, Jakobsen JR. 1999. Changes in root length from early to mid-adulthood: resorption or apposition? Am J Orthod Dentofacial Orthop 115:563-568.

Brezniak N, Wasserstein A. 1993a. Root resorption after orthodontic treatment: Part 1. literature review. Am J Orthod Dentofacial Orthop 103:62-75.

Brezniak N, Wasserstein A. 1993b. Root resorption after orthodontic treatment: Part 2. literature review. Am J Orthod Dentofacial Orthop 103:138-146.

Carlson H. 1944. Studies on the rate and amount of eruption of certain human teeth. Am J Orthod Oral
Surg 30:575-588.

Cooley WW, Lohnes PR. 1971. Multivariate data analysis. New York: John Wiley \& Sons, Inc.

De Vito C, Saunders SR. 1990. A discriminant function analysis of deciduous teeth to determine sex. J Forensic Sci 35:845-858.

Ditch LE, Rose JC. 1972. A multivariate dental sexing technique. Am J Phys Anthropol 37:61-64.

Garn SM, Cole PE, Van Alstine WL. 1979. Sex discriminatory effectiveness using combinations of root lengths and crown diameters. Am J Phys Anthropol 50:115-118.

Garn SM, Lewis AB, Swindler DR, Kerewsky RS. 1967. Genetic control of sexual dimorphism in tooth size. J Dent Res 46:963-972.

Garn SM, Van Alstine WL Jr, Cole PE. 1978a. Intraindividual root-length correlations. J Dent Res 57:270.

Garn SM, Van Alstine WLJr, Cole PE. 1978b. Relationship between root lengths and crown diameters of corresponding teeth. J Dent Res 57:636.

Gorsuch R. 1983. Factor analysis, 2nd ed. Hillsdale: Lawrence Erlbaum Publishers.

Halstead CL, Hoard BC. 1991. Dental radiology and oral pathology. Curr Probl Diagn Radiol 20:187-235.

Harris EF. 2000. External apical root resorption resulting from orthodontic tooth movement. Semin Orthod 6:183-194.

Harris EF, Bailit HL. 1988. A principal components analysis of human odontometrics. Am J Phys Anthropol 75:87-99.

Harris EF, McKee JH. 1990. Tooth mineralization standards for blacks and whites from the middle southern United States. J Forensic Sci 35:859-872.

Harris EF, Robinson QC, Woods MA. 1993. An analysis of causes of apical root resorption in patients not treated orthodontically. Quintessence Int 24:417-428.

Henderson AM. 1975. Dental Field Theory: An Application to Primate Dental Evolution. Ph.D. dissertation, University of Colorado, Boulder.

Julien KC, Buschang PH, Throckmorton GS, Dechow PC. 1996. Normal masticatory performance in young adults and children. Arch Oral Biol 41:69-75.

Kaiser HF. 1970. A second generation Little Jiffy. Psychometrika 35:401-415.

Kieser JA, Groeneveld HT. 1989. Allocation and discrimination based on human odontometric data. Am J Phys Anthropol 79:331-338.

Koppe T, Swindler DR. 2004. Metric sexual dimorphism in the deciduous teeth of Old World monkeys. Ann Anat 186:367-374.

Kovacs I. A systematic description of dental roots. In: Dahlberg AA, ed. Dental morphology and evolution. Chicago: University of Chicago Press.

Krogman WM, Iscan MY. 1986. The human skeleton in forensic medicine, 2nd ed. Springfield: Charles C. Thomas Publisher. 
Levers BGH, Darling AI. 1983. Continuous eruption of some adult human teeth of ancient populations. Arch Oral Biol 28:401-408.

Manning JT. 2002. Digit ratio: a pointer to fertility, behaviour, and health. New Brunswick, NJ: Rutgers University Press.

Moorrees CFA, Reed RB. 1964. Correlations among crown diameters of human teeth. Arch Oral Biol 9:685-697.

Nyman S, Lindhe J, Ericsson I. 1978. The effect of progressive tooth mobility on destructive periodontitis in the dog. J Clin Periodontol 5:213225.

Owsley DW, Webb RS. 1983. Misclassification probability of dental discrimination functions for sex determination. J Forensic Sci 28:181-185.

Pearson K, Davin A. 1924. On the biometric constants of the human skull. Phil Mag, series 6, 2:559-572.

Potter RH, Yu P-L, Dahlberg AA, Merritt AD, Conneally PM. 1968. Genetic structure of tooth size factors in size factors in Pima Indian families. Am J Hum Genet 20:89-100.

Rhee SH, Nahm DS. 2000. Triangular-shaped incisor crowns and crowding. Am J Orthod Dentofacial Orthop 118:624-628.

Rohlf FJ, Sokal RR. 1981. Statistical tables, 2nd ed. San Francisco: WH Freeman and Company.

Sciulli PW, Williams JA, Gugelchuk GM. 1977. Canine size: an aid in sexing prehistoric Amerindians. J Dent Res 56:1424.

Shafer WG, Hine MK, Levy BM. 1983. A textbook of oral pathology, 4th ed. Philadelphia: WB Saunders Company.
Solow B. 1966. The pattern of craniofacial associations: A morphological and methodological correlation and factor analysis study of young adult males. Acta Odont Scand, suppl 46:1-174.

Swindler DR. 2002. Primate dentition: an introduction to the teeth of non-human primates. Cambridge: Cambridge University Press.

Tanner JM, Prader A, Habich H, Ferguson-Smith MA. 1959. Genes on the $\mathrm{Y}$ chromosome influencing rate of maturation in man: skeletal age studies in children with Klinefelter's (XXY) and Turner's (XO) syndromes. Lancet 2:141-144.

Teschler-Nicola M, Prossinger H.1998. Sex determination using tooth dimensions. In: Alt KW, Rösing FW, Teschler-Nicola M, editors. Dental anthropology: fundamentals, limits, and prospects. Wien: Springer, p 479-500.

Thomas HF. 1995. Root formation. Int J Dev Biol 3:231237.

Ubelaker DH. 1999. Human skeletal remains, 3rd ed. Washington: Taraxacum.

Whittaker DK, Griffiths S, Robson A, Roger-Davies P, Thomas G, Molleson T. 1990. Continuing tooth eruption and alveolar crest height in an eighteenthcentury population from Spitalfields, east London. Arch Oral Biol 35:81-85.

Winer BJ, Brown DR, Michels KM. 1991. Statistical principles in experimental design, 3rd ed. New York: McGraw-Hill Book Company.

Wittwer-Backofen U, Gampe J, Vaupel JW. 2004. Tooth cementum annulation for age estimation: results from a large known-age validation study. Am J Phys Anthropol 123:119-129.

Zeisz RC, Nuckolls J. 1949. Dental anatomy. St Louis: CV Mosby Company. 